Article

\title{
Genotypic Variation in Seedling Tolerance to Aluminum Toxicity in Historical Maize Inbred Lines of Zambia
}

\author{
Chanda Richard ${ }^{1,2, *}$, Kalaluka Munyinda ${ }^{3}$, Theresa Kinkese ${ }^{3}$ and David S. Osiru ${ }^{2}$ \\ 1 Seed Control and Certification Institute, P.O. Box 350199, Chilanga 3201, Zambia \\ 2 College of Agriculture and Environmental Science, Makerere University, P.O. Box 7062, \\ Kampala 7010, Uganda; E-Mail: dsoosiru@caes.mak.ac.ug \\ 3 Department of Plant Science, University of Zambia, P.O. Box 32379, Lusaka 10101, Zambia; \\ E-Mails: kalalukamunyinda@yahoo.com (K.M.); tkinkense@gmail.com (T.K.) \\ * Author to whom correspondence should be addressed; E-Mail: edchazm@gmail.com or \\ scci@zamnet.zm; Tel.: +260-978-095-332; Fax: +260-211-278-170.
}

Academic Editor: Brion Duffy

Received: 17 March 2015 / Accepted: 5 May 2015 / Published: 12 June 2015

\begin{abstract}
Maize (Zea mays L) is the most important food grain in sub-Saharan Africa and is mostly grown by small-scale farmers under rainfed conditions. Aluminum toxicity caused by low $\mathrm{pH}$ is one of the abiotic factors limiting maize production among smallholder farmers. Therefore, breeding maize hybrids that are tolerant to aluminum toxicity will sustain and increase maize production in these areas. Hence this study was undertaken to assess the genotypic variation for aluminum toxicity in maize inbred lines. Fourteen maize inbred lines of historical importance that are used in maize hybrid breeding in Zambia were studied for seedling root variation under different aluminum concentrations using hydroponic conditions. The aluminum tolerance membership index based on three traits (actual root length, relative root length and root length response) classified genotypes L3233 and L1214 as highly tolerant, L5527 and ZM421 as tolerant, and L12, L3234, and ZM521 as intermediate. The high PCV, GCV, and heritability observed for the root traits indicate that opportunities for selection and breeding for aluminum tolerance among Zambian inbred lines exist. Furthermore, the study indicated that a higher genetic gain would be expected from net root growth followed by shoot length response as selection traits, thus supporting the use of root traits for aluminum tolerance screening.
\end{abstract}


Keywords: maize; aluminum toxicity; seedling traits; phenotypic coefficient of variation; genotypic coefficient of variation

\section{Introduction}

Maize is the major source of energy in sub-Saharan Africa, grown mostly by smallholder farmers [1]; as such, the crop is cultivated across a wide range of environments. Drought and low fertilizer input are two major constraints affecting maize production in addition to aluminum toxicity resulting from low $\mathrm{pH}[2,3]$. Soil acidity and aluminum toxicity are common in tropical and subtropical regions [2,3]. In these areas, maize yield reductions due to toxic levels of aluminum and manganese as well as deficiencies of phosphorus, calcium, and magnesium are common [4,5]. In southern Africa, large areas of acidic soils with free aluminum ions $\left(\mathrm{Al}^{+3}\right)$ exist in $\mathrm{Zambia}$ and Mozambique [6].

In Zambia, aluminum toxicity and low $\mathrm{pH}$ have been reported in high rainfall (wetter) areas of the country, i.e., agro-ecological region III, which covers the northern parts of Zambia [7,8]. The soils are acidic with medium to high phosphorus (1-3 ppm) fixing capacity [9]. The aluminum saturation is mostly in the range of $53 \%$ to $80 \%$ with limited places having $80 \%$ to $100 \%$ [10]. It has been estimated that a high level of soil acidity prevails throughout $98 \%$ of Zambia's maize fields [11], reducing yield to practically nil in high acid soils [8]. In these soils, it has been observed that low $\mathrm{pH}$ and high concentrations of aluminum and manganese are the major factors causing soil infertility [3,12]. In view of the above, maize does not respond to fertilizer application, especially basal dressing [11]. Despite the high levels of aluminum and low $\mathrm{pH}$, the northern regions of Zambia (region III) have been predicted to be the main agricultural food basket of the country as the southern and central parts of Zambia (regions I and II, respectively) become more prone to drought due to climate change [13]. Thus increasing and sustaining maize productivity in these areas implies the usage of acid-tolerant genotypes and/or amelioration of soil acidity [14]. Ameliorating factors are expensive and out of reach for most resource-poor farmers. In addition, the ameliorating factors have been known to destabilize the balance of the ecosystem [15]. Therefore, developing acid-tolerant maize genotypes is an effective and sustainable way of alleviating the impact of Al toxicity in maize production areas. Studies have shown that Al-tolerant maize genotypes outperformed the adapted local and susceptible genotypes by $13 \%$ and $61 \%$, respectively [16]. These results suggest that growing Al-tolerant maize genotypes will ensure a high sustained maize productivity.

Screening and selection for Al tolerance in maize involves field evaluation for more than one cropping season [17]. However, the high coefficient of variation resulting from spatial variation in the soils poses a challenge to field evaluation [17] and eventually affects the reliability of the results. Therefore, laboratory hydroponic studies of root traits offer another option if the laboratory results are correlated to field performance under the same stress conditions [17-19]. In maize, laboratory studies on seedling traits have been reported to be highly correlated to field performance for low nitrogen conditions [20], nutrient and water use efficiency [21], and weak correlation for aluminum toxicity [19]. Ouma et al. (2013), using relative net root growth (RNRG) of maize seedling under 
aluminum toxicity, were able to predict $24 \%$ and $35 \%$ of field performance. The high heritability and low coefficient of variation of root traits makes them amenable for breeding studies [22]. Hence, root traits have been effectively used for screening crops for aluminum tolerance in breeding programs [21,23]. In Zambia, most hybrids were bred for high grain yield and general adaptability, which involved multi-location and multi-season agronomic trials. This could have resulted in co-selection for aluminum tolerance in parents. Therefore, the study was conducted on historical maize inbred lines with a view to (a) quantifying the genetic variance, heritability, and expected genetic advance; and (b) identifying the traits accounting for most of the variation among the inbred lines.

\section{Material and Methods}

\subsection{Plant Materials}

The response of maize inbred lines to aluminum stress was determined in the tissue culture laboratory of the University of Zambia in the school of Plant Sciences, using test tubes. The 11 maize inbreds and three open maize pollinated varieties used in the study were supplied by the Zambia Agricultural Research Institute (ZARI).

\subsection{Hydroponic Experiment}

The seeds were first pre-germinated on filter paper in petri dishes. After germination, the roots of the seedlings were allowed to elongate to at least a uniform length. Thereafter, the seedlings were transferred to a test tube containing a diluted nutrient solution, after measuring the initial root length. The nutrient solution used for plant growth had the following composition (in milligrams per liter, $\mathrm{mg} / \mathrm{L}$ ): $48.1 \mathrm{Ca}, 14.6 \mathrm{Mg}, 42.61 \mathrm{~N}, 23.5 \mathrm{~K}, 0.02 \mathrm{Na}, 0.03 \mathrm{Cl}, 0.03 \mathrm{Mn}, 0.06 \mathrm{Cu}, 0.03 \mathrm{Mo}, 0.16 \mathrm{Zn}$, $1.67 \mathrm{Fe}$ (added as $\mathrm{FeSO}_{4} \cdot 7 \mathrm{H}_{2} \mathrm{O}$ ), and $0.32 \mathrm{~B}$ [24]. Different aluminum concentrations in the nutrient solution were achieved by dissolving $0,4,8,12,16$, and 20 milligrams per liter $(\mathrm{mg} / \mathrm{L})$ of aluminum sulfate $\left(\mathrm{Al}_{2}\left[\mathrm{SO}_{4}\right]_{3}\right)$. The $\mathrm{pH}$ of the nutrient solution was then adjusted to 4.2 and left unadjusted thereafter. Each treatment was replicated four times.

The plants were grown at room temperature $\left(28^{\circ} \mathrm{C}\right)$ with an average day length of $13 \mathrm{~h}$ for 10 days. After 10 days, the plants were harvested and separated into roots and shoots. The traits (Table 1) were recorded. The root and shoot dry mass was determined by drying the respective plant parts in an oven for 4 days at $70{ }^{\circ} \mathrm{C}$.

In addition, the following traits were derived:

$$
\begin{gathered}
\% \text { response }=\frac{(\text { Growth Parameteres in Control })-(\text { Growth Parameteres in Al treatments })}{\text { Growth Parameteres in Control }} \times 100 \\
{[25] .} \\
\text { Relative Root Length }(\mathrm{RRL}) \%=\frac{\text { root length in Al soluthon }}{\text { root length in control }} \times 100[25,26] . \\
\text { Specific Root Length }(\mathrm{SRL})=\frac{\text { Total Root Length }}{\text { Root biomass }}[27] .
\end{gathered}
$$

Actual root length $(\mathrm{ARL})=$ Final root length $($ FRL)-Initial root length (IRL).

$$
F_{i j}=\frac{X_{i j}-X_{\min }}{X_{\max }-X_{\min }} \text { and } \mathrm{F}_{i}=\text { average of } \mathrm{F}_{i j}[28] \text {, where: }
$$


$\mathrm{F}_{i j}=$ membership index value of the $i$ th inbred line, $j$ th trait

$\mathrm{X}_{i j}=$ ratio of the $i$ th inbred line, $j$ th trait

$\mathrm{X}_{\min }=$ minimum ratio of the trait

$\mathrm{X}_{\max }=$ maximum ratio of the trait

$\mathrm{F}_{i}=$ membership index averaged over $\mathrm{n}$ traits of the $i$ th accession

Table 1. Maize root seedling characteristics measured in the study.

\begin{tabular}{cc}
\hline Trait & Details \\
\hline Initial root length (IRL) & $\begin{array}{c}\text { Length of roots recorded before the seedlings } \\
\text { were transferred into the nutrient solution }\end{array}$ \\
\hline Final root length (FRL) & $\begin{array}{c}\text { Root length recorded after seedlings } \\
\text { have been exposed to nutrient solution }\end{array}$ \\
\hline Number of roots (NOR) & $\begin{array}{c}\text { Number of roots formed after the seedlings } \\
\text { have been exposed to aluminum stress }\end{array}$ \\
\hline $\begin{array}{c}\text { Shoot or Root dry matter } \\
\text { (SDM or RDM) }\end{array}$ & The weight of root or shoot growth parts \\
\hline $\begin{array}{c}\text { Total dry matter (TDM) } \\
\text { Shoot Length (SL) }\end{array}$ & $\begin{array}{c}\text { The weight of shoot and root growth parts } \\
\text { (Sum of root and shoot biomass) }\end{array}$ \\
\hline $\begin{array}{c}\text { Shoot length response or } \\
\text { root length response }\end{array}$ & $\begin{array}{c}\text { Length of the shoot measured after seedlings } \\
\text { have been exposed to aluminum stress }\end{array}$ \\
\hline $\begin{array}{c}\text { Net root growth (NRG) } \\
\text { This was calculated by using Equation (1). }\end{array}$ \\
\hline $\begin{array}{c}\text { Shoot length: shoot dry } \\
\text { matter ratio (SLSDMratio) }\end{array}$ & $\begin{array}{c}\text { This was calculated by subtracting the root length of } \\
\text { maize seedlings in aluminum stress from the control. }\end{array}$ \\
\hline $\begin{array}{c}\text { Shoot: root dry matter ratio } \\
\text { (SRDMratio) }\end{array}$ & $\begin{array}{c}\text { Estimated by dividing shoot dry } \\
\text { matter by shoot length }\end{array}$ \\
\hline $\begin{array}{c}\text { Shoot: root length ratio } \\
\text { (SLRLratio) }\end{array}$ & $\begin{array}{c}\text { Estimated by dividing shoot dry } \\
\text { matter by root dry matter }\end{array}$ \\
\hline Estimated by dividing shoot length by root length \\
\hline
\end{tabular}

For each trait and concentration, the membership index was calculated, and then the membership index averaged over all the traits. The mean overall membership index was then used as an indicator for Al tolerance. The rank of each inbred line to aluminum stress was then classified as Table 2:

Table 2. Aluminum tolerance membership index.

\begin{tabular}{cc}
\hline Rank 1: $\mathbf{F}_{\boldsymbol{i}} \geq \mathbf{0 . 8}$ & (highly tolerant) \\
\hline Rank 2: $0.6 \geq \mathrm{F}_{i}<0.8$ & (tolerant) \\
Rank 3: $0.4 \geq \mathrm{F}_{i}<0.6$ & (intermediate tolerance) \\
Rank 4: $0.2 \geq \mathrm{F}_{i}<0.4$ & (susceptible) \\
$\operatorname{Rank} 5: \mathrm{F}_{i}<0.2$ & (highly susceptible) \\
\hline
\end{tabular}




\subsection{Statistical Analysis}

The Analysis Of Variance (ANOVA), variance components, and broad sense heritability (Hbs) were calculated using a web based software, the PBSTAT [29]. Heritability, genotypic, and phenotypic variances (GCV and PCV, respectively) were estimated as suggested by Singh and Chaudhary [30]. The PCV and GCV were calculated as:

$$
\begin{gathered}
\operatorname{PCV}(\%)=\frac{\sqrt{V}_{p}}{X_{\text {mean }}} \times 100 ; V_{p}=\text { phenotypic variance } \\
\operatorname{PCV}(\%)=\frac{\sqrt{V}_{g}}{X_{\text {mean }}} \times 100 ; V_{g}=\text { phenotypic variance, where }
\end{gathered}
$$

$\mathrm{PCV}=$ Phenotypic Coefficient of Variability

$\mathrm{GCV}=$ Genotypic Coefficient of Variability,

$X_{\text {mean }}=$ mean of the character

Heritability in the broad sense, genetic advance at 5\% intensity, and genetic gain as a percentage of trait mean were calculated as:

$$
\begin{gathered}
\mathrm{Hbs}_{\mathrm{bs}}=\frac{V_{g}}{V_{p}} \times 100 ; \mathrm{H}_{\mathrm{bs}}=\text { Heritability }(\text { broad sense }) \\
\text { Genetic advance }(\mathrm{GA})=\frac{V_{g}}{V_{p}} \times \sqrt{V_{p}} \times k ; \\
\text { Genetic gain }(\%)=\frac{G A}{X_{\text {mean }}} \times 100, \text { where: }
\end{gathered}
$$

$\mathrm{K}=$ selection differential at $5 \%$ selection intensity. The value of $k=2.06$.

The genetic advance as percent of mean (GG), genotypic coefficient of variability (GCV), and phenotypic coefficients of variability (PCV) were categorized as low $(0 \%-10 \%)$, moderate $(10-20 \%)$, or high $(>20 \%)$ [31,32], while heritability was categorized as low $(0 \%-30 \%)$, moderate $(30 \%-60 \%)$, or high $(>60 \%)$ [33]. The principal component analysis, cluster analysis, and association among traits were calculated using Minitab version 16 software.

\section{Results}

\subsection{Analysis of Variance (ANOVA) for Seedling Traits}

The interaction between aluminum concentration and genotypes was highly significant $(p<0.01)$ for all the traits except for shoot length response (SLR), number of roots formed (NOR), and Shoot Length-Root Length Ratio (SLRLratio) (Table 3). This indicates that the genotypic performance was not the same across aluminum concentrations for these traits. The main effects (genotype and environment) were also significant for most of the traits, indicating that aluminum concentration had different effects while superior genotypes can be found (Table 3). The mean performance of each of the genotype is shown in Table 3. The superior performance of the genotypes in aluminum toxic solutions is exhibited in RRL, SRL, and NRG traits, with some genotypes exhibiting negative net root growth (impaired root growth) compared to the control (Table 3 ). 
Table 3. Mean performance of maize genotypes averaged across all aluminum concentrations, and probability of main effects and their interaction.

\begin{tabular}{|c|c|c|c|c|c|c|c|c|c|c|c|c|c|c|c|c|}
\hline Genotype & IRL & FRL & ARL & SRL & RRL & RLR & SL & SLR & SLSDM Ratio & NOR & RDM & SDM & TDM & SRDM Ratio & SLRL Ratio & NRG \\
\hline POOL 16 & 1.81 & 16.47 & 14.66 & 692.04 & 101.49 & -0.63 & 6.17 & -11.35 & 172.09 & 3.38 & 0.03 & 0.04 & 0.08 & 1.83 & 0.45 & 1.20 \\
\hline L12 & 2.33 & 7.81 & 5.49 & 521.96 & 113.39 & 21.50 & 3.21 & 2.32 & 156.95 & 2.00 & 0.02 & 0.03 & 0.04 & 2.72 & 0.41 & -6.04 \\
\hline L143 & 1.13 & 10.13 & 8.99 & 491.29 & 100.26 & 2.68 & 6.06 & 0.24 & 216.46 & 3.92 & 0.02 & 0.03 & 0.06 & 1.64 & 0.89 & 1.99 \\
\hline L710 & 1.13 & 5.70 & 4.56 & 996.63 & 102.21 & -0.62 & 12.25 & -9.04 & 661.89 & 1.17 & 0.01 & 0.02 & 0.03 & 4.92 & 2.97 & -1.57 \\
\hline L911 & 1.45 & 6.53 & 4.68 & 1039.71 & 94.41 & -23.79 & 5.96 & -1.70 & 199.25 & 1.54 & 0.01 & 0.04 & 0.05 & 7.73 & 1.25 & -0.02 \\
\hline L913 & 2.68 & 14.17 & 11.49 & 504.79 & 93.29 & -1.71 & 5.71 & -16.59 & 133.72 & 3.71 & 0.03 & 0.05 & 0.08 & 2.08 & 0.69 & 4.25 \\
\hline L917 & 2.35 & 8.18 & 5.83 & 149.13 & 76.64 & -27.19 & 5.85 & -5.92 & 176.08 & 3.54 & 0.04 & 0.04 & 0.08 & 1.08 & 1.45 & -3.56 \\
\hline L1214 & 1.89 & 12.17 & 10.28 & 529.29 & 150.21 & 89.03 & 5.88 & -14.31 & 111.20 & 2.96 & 0.03 & 0.06 & 0.08 & 3.74 & 0.69 & 3.51 \\
\hline L3233 & 1.70 & 11.56 & 9.87 & 1152.00 & 149.25 & 85.50 & 5.79 & -3.48 & 308.92 & 2.63 & 0.01 & 0.03 & 0.04 & 3.50 & 1.13 & -0.14 \\
\hline L3234 & 3.05 & 17.40 & 14.34 & 1129.04 & 127.58 & 44.96 & 5.63 & 23.95 & 168.29 & 1.92 & 0.02 & 0.04 & 0.06 & 2.54 & 0.45 & 3.13 \\
\hline ZM421 & 2.19 & 16.50 & 14.31 & 323.08 & 146.23 & 68.85 & 6.83 & -5.45 & 155.00 & 3.21 & 0.06 & 0.05 & 0.10 & 0.99 & 0.55 & -0.29 \\
\hline ZM521 & 2.17 & 15.47 & 13.30 & 311.54 & 123.18 & 45.60 & 6.52 & -1.83 & 206.21 & 5.08 & 0.05 & 0.03 & 0.08 & 0.77 & 0.55 & -1.54 \\
\hline L5522 & 2.06 & 9.90 & 7.84 & 844.00 & 92.02 & -11.78 & 5.10 & 2.67 & 159.95 & 1.71 & 0.02 & 0.04 & 0.07 & 2.79 & 0.63 & -3.20 \\
\hline L5527 & 2.10 & 13.54 & 11.44 & 936.29 & 123.36 & 45.58 & 7.48 & 32.09 & 136.48 & 2.17 & 0.03 & 0.06 & 0.10 & 5.37 & 0.83 & 3.46 \\
\hline Mean & 2.003 & 11.824 & 9.791 & 687.199 & 113.823 & 24.141 & 6.317 & -0.600 & 211.606 & 2.781 & 0.027 & 0.040 & 0.068 & 2.979 & 0.924 & 0.084 \\
\hline \multicolumn{17}{|c|}{ Probability of main effects and their interactions } \\
\hline Genotype & 0.000 & 0.033 & 0.049 & 0.065 & 0.007 & 0.027 & 0.287 & 0.869 & 0.002 & 0.167 & 0.092 & 0.000 & 0.000 & 0.034 & 0.317 & 0.756 \\
\hline Environment & 0.426 & 0.898 & 0.785 & 0.497 & 0.519 & 0.346 & 0.572 & 0.815 & 0.933 & 0.557 & 0.942 & 0.603 & 0.842 & 0.515 & 0.605 & 0.573 \\
\hline interaction & 0.000 & 0.000 & 0.000 & 0.000 & 0.000 & 0.000 & 0.000 & 0.000 & 0.000 & 0.000 & 0.000 & 0.000 & 0.000 & 0.000 & 0.000 & 0.000 \\
\hline
\end{tabular}

$\mathrm{IRL}=$ Initial root length, FRL = Final root length, ARL = Actual root length, SRL = specific root length, RRL = relative root length, RLR $=$ Root length response, $\mathrm{SL}=$ shoot length, SLR $=$ Shoot length response, SLSDMratio $=$ Shoot length-shoot dry matter ratio, NOR $=$ Number of roots, RDM $=$ root dry matter, SDM $=$ shoot dry matter, TDM = total dry matter, SRDM ratio = shoot-root dry matter ratio, SLRL Ratio = shoot root length ratio, and NRG $=$ net root growth. 


\subsection{Phenotypic and Genotypic Coefficients of Variation, Heritability, and Genetic Advance as Percent} of the Mean

The genetic variance $\left(V_{G}\right)$ was greater than the interaction variance $\left(V_{G X E n}\right)$ for FRL, $A R L, R R L$, RLR, SL, SLR, SLSDMratio, NOR, RDM, TDM, and SLRLratio (Table 4). Therefore, aluminum concentration had less influence on these traits. The broad sense heritability ranged from $48.1 \%$ for SRL to $94.0 \%$ for SLSDMratio with all the traits having high heritability ( $>60 \%)$, except for SRL. The PCV and GCV ratios for most of the traits were almost equal. The phenotypic variance $\left(V_{p}\right)$ was higher than the genotypic variance $\left(V_{G}\right)$ for all the traits, except for RDM and TDM. All the traits studied had high GG, with the highest (5097.4) observed for NRG, followed by SLR (3313.6). The least GG was observed for RR (31.9\%).

Table 4. Estimates of variance components, heritability, genetic gain, and genetic advance as percent of mean, phenotypic, and genotypic coefficients of variability for 14 inbreds tested in six aluminum concentrations *.

\begin{tabular}{cccccccccc}
\hline Variable & Grand Mean & $\mathbf{V}_{\mathbf{G}}$ & $\mathbf{V}_{\mathbf{G x E n}}$ & $\mathbf{\mathbf { V } _ { \mathbf { P } }}$ & $\mathbf{h}^{2}{ }_{\text {bs }} \mathbf{( \% )}$ & $\mathbf{P C V}$ & $\mathbf{G C V}$ & $\mathbf{G A}$ & $\mathbf{G G}$ \\
\hline IRL & 2.00 & 0.2031 & 0.4339 & 0.2947 & 68.9 & 27.1 & 22.5 & 0.77 & 38.5 \\
FRL & 11.82 & 13.716 & 5.553 & 15.2272 & 90.1 & 33.0 & 31.3 & 7.24 & 61.2 \\
ARL & 9.79 & 11.6236 & 7.4616 & 13.4773 & 86.3 & 37.5 & 34.8 & 6.52 & 66.6 \\
SRL & 687.20 & $52,020.44$ & $158,743.45$ & $108,080.2273$ & 48.1 & 47.8 & 33.2 & 325.96 & 47.4 \\
RRL & 113.82 & 412.6663 & 351.6464 & 548.0072 & 75.3 & 20.6 & 17.8 & 36.31 & 31.9 \\
RLR & 24.14 & 1224.88 & 672.9026 & 1531.7734 & 80.0 & 162.1 & 145.0 & 64.47 & 267.1 \\
SL & 6.32 & 3.511 & 1.2157 & 3.8265 & 91.8 & 31.0 & 29.7 & 3.70 & 58.5 \\
SLR & -0.60 & 130.6968 & 79.2851 & 183.4006 & 71.3 & 2257.1 & 1905.4 & 19.88 & 3313.5 \\
SLSDMratio & 211.61 & $17,912.03$ & 3212.58 & $19,060.2367$ & 94.0 & 65.2 & 63.2 & 267.27 & 126.3 \\
NOR & 2.78 & 1.0852 & 0.0806 & 1.2036 & 90.2 & 39.4 & 37.5 & 2.04 & 73.3 \\
RDM & 0.03 & 0.0002 & 0.0001 & 0.0002 & 90.3 & 52.1 & 52.1 & 0.03 & 107.3 \\
SDM & 0.04 & 0.0001 & 0.0001 & 0.0002 & 88.3 & 35.4 & 25.0 & 0.01 & 36.4 \\
TDM & 0.07 & 0.0005 & 0.0002 & 0.0005 & 87.8 & 33.0 & 33.0 & 0.05 & 67.9 \\
SRDMratio & 2.98 & 2.5002 & 3.6912 & 3.8111 & 65.6 & 65.5 & 53.1 & 2.64 & 88.6 \\
SLRLRATIO & 0.92 & 0.3902 & 0 & 0.4806 & 81.2 & 75.0 & 67.6 & 1.16 & 125.4 \\
NRG & 0.08 & 6.3832 & 11.5206 & 9.3671 & 68.2 & 3631.2 & 2997.5 & 4.30 & 5097.4 \\
\hline
\end{tabular}

* En = Environment, related to different aluminum concentrations; IRL = Initial root length, FRL = Final root length, $\mathrm{ARL}=$ Actual root length, $\mathrm{SRL}=$ specific root length, $\mathrm{RRL}=$ relative root length, $\mathrm{RLR}=$ Root length response, $\mathrm{SL}=$ shoot length, SLR $=$ Shoot length response, SLSDMratio $=$ Shoot length-shoot dry matter ratio, RDM $=$ root dry matter, SDM = shoot dry matter, TDM = total dry matter, SRDM ratio = shoot-root dry matter ratio, NOR $=$ Number of roots, SLRL Ratio $=$ shoot root length ratio, and NRG $=$ net root growth.

\subsection{Associations among Seedling Traits}

The correlation coefficients with $0 \leq \mathrm{r} 2 \leq 0.5,0.5<\mathrm{r} 2 \leq 0.8$ and $0.8<\mathrm{r} 2$, were classified as weak, moderate, and strong, respectively [34]. SL was significantly $(p<0.01)$ and positively correlated to SLSDMratio and SLRLratio (Table 5). FRL was positively and perfectly correlated $(r=0.99)$ to ARL. Both ARL and FRL were moderately and positively correlated to RDM and NRG, while being negatively correlated to SLRLratio. The magnitudes of the correlation coefficient was similar in each of the traits for both ARL and FRL. NOR was moderately and negatively correlated to SRDMratio and SRL, while positively and moderately correlated to RDM only. 
Table 5. Pearson correlation coefficients among 15 seedling traits of 14 maize inbred lines in six aluminum concentrations $(n=84)$.

\begin{tabular}{|c|c|c|c|c|c|c|c|c|c|c|c|c|c|c|c|}
\hline Trait & IRL & FRL & ARL & SRL & RRL & RLR & SL & SLR & SLSDM Ratio & NOR & RDM & SDM & TDM & SRDM Ratio & SLRL Ratio \\
\hline $\mathrm{FRL}^{2}$ & $0.56^{1 *}$ & & & & & & & & & & & & & & \\
\hline ARL & 0.45 & $0.99 * *$ & & & & & & & & & & & & & \\
\hline SRL & -0.18 & -0.11 & -0.10 & & & & & & & & & & & & \\
\hline RRL & 0.09 & 0.46 & 0.49 & 0.16 & & & & & & & & & & & \\
\hline RLR & 0.16 & 0.49 & 0.51 & 0.09 & $0.98 * *$ & & & & & & & & & & \\
\hline SL & -0.48 & -0.18 & -0.12 & 0.24 & -0.02 & -0.05 & & & & & & & & & \\
\hline SLR & 0.29 & 0.19 & 0.16 & 0.43 & 0.14 & 0.14 & -0.07 & & & & & & & & \\
\hline SLSDM ratio & $-0.57 *$ & -0.48 & -0.42 & 0.36 & -0.09 & -0.14 & $0.82 * *$ & -0.18 & & & & & & & \\
\hline NOR & 0.14 & 0.48 & 0.50 & $-0.73 * *$ & 0.05 & 0.14 & -0.22 & -0.33 & -0.36 & & & & & & \\
\hline RDM & 0.39 & $0.57^{*}$ & $0.56 *$ & $-0.76 * *$ & 0.20 & 0.25 & -0.09 & -0.11 & -0.43 & $0.67 * *$ & & & & & \\
\hline SDM & 0.39 & 0.43 & 0.40 & -0.14 & 0.27 & 0.31 & -0.23 & 0.17 & $-0.67 * *$ & 0.07 & 0.40 & & & & \\
\hline TDM & 0.39 & $0.64 *$ & $0.62 *$ & -0.50 & 0.12 & 0.18 & -0.14 & 0.12 & $-0.64 * *$ & 0.50 & $0.81 * *$ & $0.78 * *$ & & & \\
\hline SRDM ratio & -0.40 & -0.50 & -0.49 & $0.70 * *$ & -0.02 & -0.10 & 0.28 & 0.23 & 0.27 & $-0.72 * *$ & $-0.65 * *$ & 0.09 & -0.37 & & \\
\hline SLRL ratio & $-0.57 *$ & $-0.66 * *$ & $-0.62 *$ & 0.26 & -0.28 & -0.30 & $0.82 * *$ & -0.20 & $0.89 * *$ & -0.39 & -0.40 & -0.45 & -0.50 & 0.41 & \\
\hline NRG & 0.08 & $0.53 *$ & $0.56 *$ & 0.24 & 0.29 & 0.31 & 0.15 & 0.13 & -0.22 & 0.16 & 0.01 & $0.57 *$ & 0.38 & 0.15 & -0.18 \\
\hline
\end{tabular}

$1, *=$ significant at $\mathrm{p}=0.05, * *=$ significant at $p=0.01 ;{ }^{2} \mathrm{IRL}=$ Initial root length, FRL $=$ Final root length, ARL $=$ Actual root length, SRL $=$ specific root length, $\mathrm{RRL}=$ relative root length, $\mathrm{RLR}=$ Root length response, $\mathrm{SL}=$ shoot length, $\mathrm{SLR}=$ Shoot length response, SLSDMratio $=$ Shoot length-shoot dry matter ratio, $\mathrm{RDM}=$ root dry matter, $\mathrm{SDM}=$ shoot dry matter, $\mathrm{TDM}=$ total dry matter, SRDM ratio = shoot-root dry matter ratio, NOR $=$ number of roots, SLRL Ratio $=$ shoot root length ratio, and $\mathrm{NRG}=$ net root growth. 


\subsection{Principal Component Analysis}

Principal component analysis was carried out to identify the main trait that could be used in selection for aluminum tolerance or the trait that explained much of the variation observed in maize inbred lines. The first five principal components had eigenvalues greater than 1 and were thus important in explaining the variation observed (Table 6). The first principal component explained $40.40 \%$ of the variation followed by the second component $(18.3 \%)$. The third, fourth, and fifth components explained $13.0 \%, 9.2 \%$, and $6.6 \%$ respectively. Cumulatively, all five factors explained $87.7 \%$, with the first and second component accounting for $58.7 \%$ together. The traits FRL, ARL, SLSDMratio, RDM, TDM, and SLRLratio loaded highest $(>0.30)$ on the first component. On the second component, SRL, RRL, RLR, SLR, NOR, SRDMratio, and SLRLratio loaded highest ( $>0.30)$. The root components (FRL, IRL, FRL, NOR, RDM) were important in the first component. The second component was largely influenced by SRL $(-0.46)$ followed by RRL $(-0.35)$. It was observed that some variables that had positive loadings in PC1 had negative loadings in PC2, except for NOR, RDM, and TDM. The first PC separated the inbreds on six traits (traits with values $\geq 0.30$ ). The second PC separated the inbreds on seven traits. Amongst all the traits, RRL and RLR appeared three times in the first five components.

Table 6. Principal component analysis of 14 maize genotypes, eigenvalues, proportion, and cumulative variance for the first six components for root morphological characters in six aluminum concentrations $(n=84)$.

\begin{tabular}{ccccccc}
\hline Value & PC 1 & PC 2 & PC 3 & PC 4 & PC 5 & PC 6 \\
\hline Eigenvalue & 6.462 & 2.932 & 2.100 & 1.477 & 1.061 & 0.892 \\
Proportion & 0.404 & 0.183 & 0.131 & 0.092 & 0.066 & 0.056 \\
Cumulative & 0.404 & 0.587 & 0.718 & 0.811 & 0.877 & 0.933 \\
Component loadings * & & & & & \\
IRL & 0.25 & -0.02 & 0.27 & 0.09 & $-\mathbf{0 . 3 4}$ & 0.23 \\
FRL & $\mathbf{0 . 3 4}$ & -0.16 & -0.14 & 0.04 & $-\mathbf{0 . 3 1}$ & -0.16 \\
ARL & $\mathbf{0 . 3 3}$ & -0.16 & -0.20 & 0.04 & -0.29 & -0.20 \\
SRL & -0.19 & $-\mathbf{0 . 4 6}$ & 0.10 & 0.07 & -0.21 & -0.18 \\
RRL & 0.15 & $-\mathbf{0 . 3 5}$ & -0.27 & $\mathbf{0 . 3 7}$ & $\mathbf{0 . 3 2}$ & 0.17 \\
RLR & 0.18 & $-\mathbf{0 . 3 2}$ & -0.27 & $\mathbf{0 . 3 6}$ & $\mathbf{0 . 3 1}$ & 0.18 \\
SL & -0.19 & -0.10 & $-\mathbf{0 . 4 9}$ & $-\mathbf{0 . 3 1}$ & -0.21 & 0.20 \\
SLR & 0.04 & $-\mathbf{0 . 3 2}$ & 0.26 & -0.01 & $-\mathbf{0 . 4 3}$ & 0.40 \\
SLSDM ratio & $-\mathbf{0 . 3 1}$ & -0.02 & $-\mathbf{0 . 3 9}$ & 0.06 & -0.21 & 0.08 \\
NOR & 0.25 & $\mathbf{0 . 3 0}$ & -0.24 & 0.02 & 0.02 & -0.29 \\
RDM & $\mathbf{0 . 3 0}$ & 0.22 & -0.21 & -0.10 & 0.01 & 0.40 \\
SDM & 0.25 & -0.20 & 0.13 & $-\mathbf{0 . 4 4}$ & $\mathbf{0 . 3 4}$ & 0.15 \\
TDM & $\mathbf{0 . 3 2}$ & 0.03 & -0.04 & $-\mathbf{0 . 4 1}$ & 0.03 & 0.22 \\
SRDMratio & -0.24 & $-\mathbf{0 . 3 3}$ & 0.16 & -0.25 & 0.27 & 0.03 \\
SLRLratio & $-\mathbf{0 . 3 2}$ & 0.03 & $-\mathbf{0 . 3 0}$ & -0.20 & -0.05 & 0.19 \\
NRG & 0.15 & $-\mathbf{0 . 3 3}$ & -0.15 & $-\mathbf{0 . 3 8}$ & -0.01 & -0.49 \\
\hline
\end{tabular}

* values $\geq 0.30$ are presented in bold face and indicates traits important for PC definition; IRL = Initial root length, FRL = Final root length, ARL = Actual root length, SRL = specific root length, RRL = relative root length, $\mathrm{RLR}=$ Root length response, $\mathrm{SL}=$ shoot length, $\mathrm{SLR}=$ Shoot length response, $\mathrm{SLSDMratio}=$ Shoot length-shoot dry matter ratio, $\mathrm{RDM}=$ root dry matter, $\mathrm{SDM}=$ shoot dry matter, TDM = total dry matter, SRDM ratio $=$ shoot-root dry matter ratio, NOR $=$ number of roots, SLRL Ratio $=$ shoot root length ratio, and $\mathrm{NRG}=$ net root growth . 


\subsection{Cluster Analysis and Similarity between Inbred Lines}

The similarity of the inbred lines based on the seedling traits is shown in Table 7. The inbred line L5522 and L911 were the closest (0.08) and the furthest (2.85) was between L3234 and L917. The principal coordinate analysis based on the Euclidean distance was used to visualize the genotypes (Figure 1). The maize genotypes were clustered in all four quadrants, with most of them in quadrant IV. The two maize populations were in quadrant II, while L12 and L1214 were in quadrant III. L710, L143, and L917 were in quadrant I, while the rest were in quadrant IV.

Table 7. Dissimilarity matrix of 14 maize genotypes based on Euclidean distance of seedling traits.

\begin{tabular}{|c|c|c|c|c|c|c|c|c|c|c|c|c|c|c|}
\hline Genotype & POOL16 & L12 & L143 & L710 & L911 & L913 & L917 & L1214 & L3233 & L3234 & ZM421 & ZM521 & L5522 & $\mathbf{L 5 5 2 7}$ \\
\hline POOL16 & 0.00 & & & & & & & & & & & & & \\
\hline L12 & 0.33 & 0.00 & & & & & & & & & & & & \\
\hline L143 & 0.66 & 0.50 & 0.00 & & & & & & & & & & & \\
\hline L710 & 1.34 & 1.24 & 0.78 & 0.00 & & & & & & & & & & \\
\hline L911 & 0.29 & 0.58 & 0.90 & 1.50 & 0.00 & & & & & & & & & \\
\hline L913 & 0.16 & 0.26 & 0.60 & 1.32 & 0.43 & 0.00 & & & & & & & & \\
\hline L917 & 2.46 & 2.29 & 1.86 & 1.49 & 2.68 & 2.38 & 0.00 & & & & & & & \\
\hline L1214 & 0.78 & 0.63 & 1.06 & 1.74 & 0.93 & 0.73 & 2.68 & 0.00 & & & & & & \\
\hline L3233 & 0.30 & 0.35 & 0.68 & 1.29 & 0.43 & 0.38 & 2.50 & 0.68 & 0.00 & & & & & \\
\hline L3234 & 0.44 & 0.64 & 1.05 & 1.69 & 0.30 & 0.56 & 2.85 & 0.78 & 0.46 & 0.00 & & & & \\
\hline ZM421 & 1.32 & 1.02 & 1.01 & 1.44 & 1.58 & 1.21 & 1.96 & 0.97 & 1.24 & 1.56 & 0.00 & & & \\
\hline ZM521 & 1.47 & 1.20 & 0.90 & 0.97 & 1.73 & 1.37 & 1.40 & 1.44 & 1.41 & 1.81 & 0.65 & 0.00 & & \\
\hline L5522 & 0.26 & 0.54 & 0.89 & 1.52 & 0.08 & 0.39 & 2.67 & 0.87 & 0.41 & 0.26 & 1.54 & 1.70 & 0.00 & \\
\hline L5527 & 0.47 & 0.63 & 1.07 & 1.72 & 0.36 & 0.57 & 2.86 & 0.74 & 0.48 & 0.08 & 1.54 & 1.80 & 0.31 & 0.00 \\
\hline
\end{tabular}

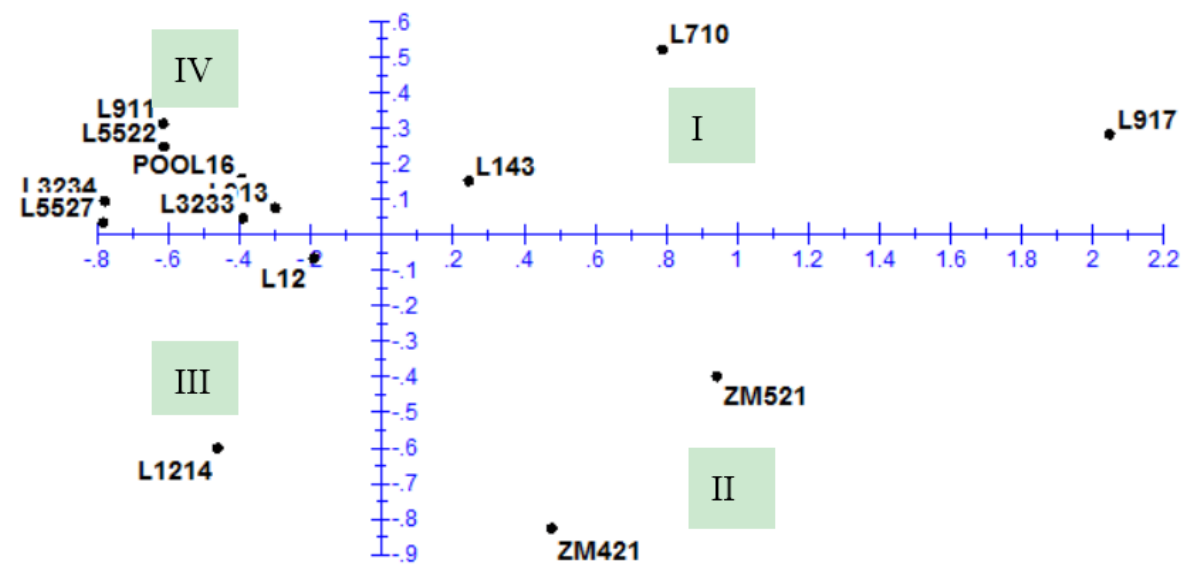

Figure 1. A plot of principal coordinate analysis of 14 genotypes based on the Euclidean distance of eight seedling traits.

The consensus dendrogram based on the Euclidean distance of quantitative traits (Figure 2) clustered maize genotypes into three major groups with a coefficient of 0.858 . Cluster 1 consisted of L911, L5522, L3234, and L5527. Cluster 2 consisted of L3233, L12, Pool16, and L913. Cluster 3 consisted of L1214, L143, L710, L917, ZM421, and ZM521. 


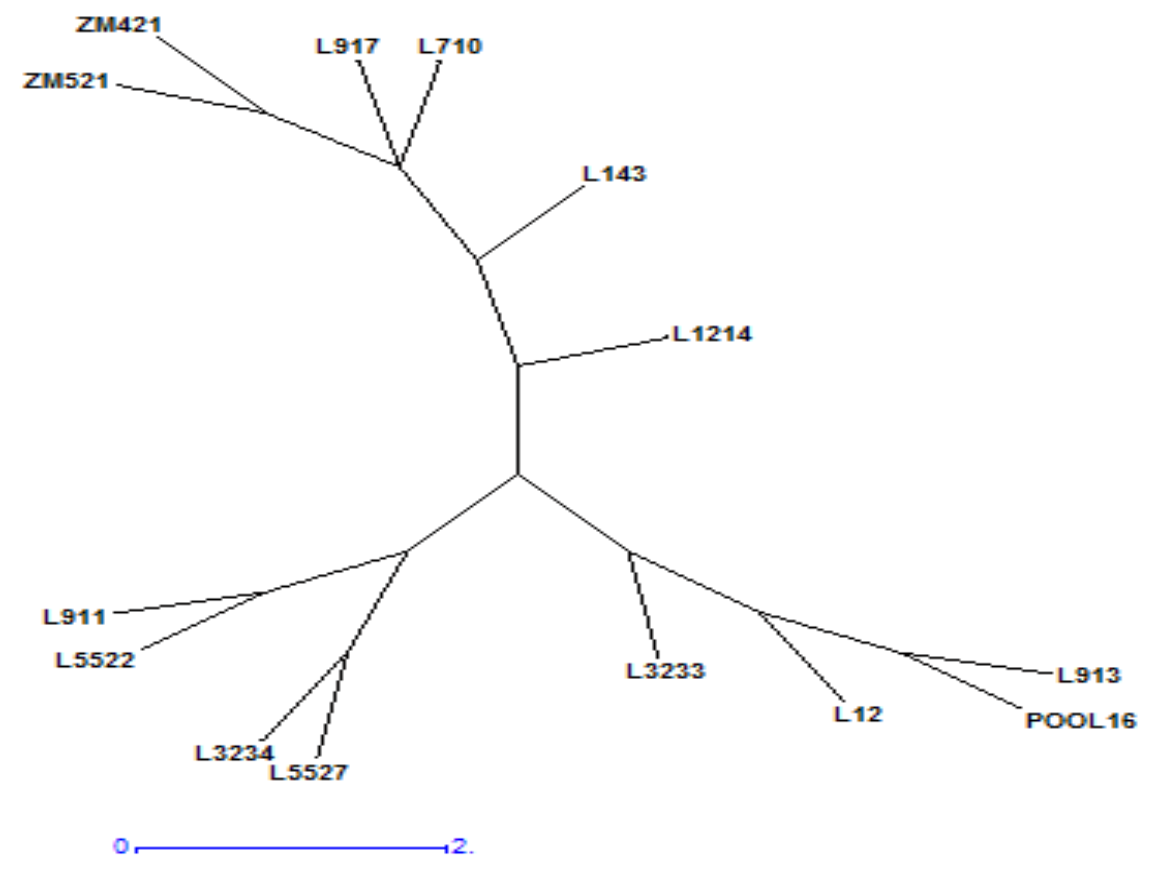

Figure 2. Dendrogram showing clustering of 14 maize genotypes.

The characteristics of the clusters are shown in Table 8. Genotypes in Clusters 1 and 3 had generally experienced reduced root net growth, while genotypes in Cluster 2 had increased net root growth. Genotypes in Cluster 2 had high SRL and high dry matter partitioning (SRDMratio) compared to those in Clusters 1 and 3. Based on these characteristics, it is apparent that genotypes in Cluster 2 possess good traits that can be used in breeding.

The root tolerance index (RTI) has been recommended as the trait to use for identifying Al-tolerant cereals in hydroponics [35]. The RTI is specific and removes the effect of genes controlling root vigor by taking the relative growth of the genotype in Al solution compared to the one without Al [35]. Therefore, ARL, RRL, and RLR were used to identify Al tolerant genotypes (Table 9). The three root traits, on average, classified seven genotypes as susceptible to Al toxicity (HS and S classes), with four genotypes being identified as tolerant (HT and $\mathrm{T}$ classes) and only three genotypes being intermediate (I class). Some genotypes were consistently classified in the same group, regardless of the trait used (Table 9). 
Table 8. Cluster membership, mean, maximum, minimum, and range of seedling characteristics of each cluster.*

\begin{tabular}{|c|c|c|c|c|c|c|c|c|c|c|c|c|c|c|c|c|c|}
\hline Cluster & Parameters & IRL & FRL & ARL & SRL & RRL & RLR & SL & SLR & $\begin{array}{c}\text { SLSDM } \\
\text { Ratio }\end{array}$ & NOR & RDM & SDM & TDM & $\begin{array}{c}\text { SRDM } \\
\text { Ratio }\end{array}$ & $\begin{array}{l}\text { SLRL } \\
\text { Ratio } \\
\end{array}$ & NRG \\
\hline \multirow{4}{*}{$\begin{array}{c}\text { Cluster 1 } \\
\text { Pool16, L12, } \\
\text { L913, L3233 }\end{array}$} & Mean & 2.13 & 12.50 & 10.38 & 717.70 & 114.36 & 26.17 & 5.22 & -7.28 & 192.92 & 2.93 & 0.02 & 0.04 & 0.06 & 2.53 & 0.67 & -0.18 \\
\hline & Max & 2.68 & 16.47 & 14.66 & 1152.00 & 149.25 & 85.50 & 6.17 & 2.32 & 308.92 & 3.71 & 0.03 & 0.05 & 0.08 & 3.50 & 1.13 & 4.25 \\
\hline & Min & 1.70 & 7.81 & 5.49 & 504.79 & 93.29 & -1.71 & 3.21 & -16.59 & 133.72 & 2.00 & 0.01 & 0.03 & 0.04 & 1.83 & 0.41 & -6.04 \\
\hline & Range & 0.98 & 8.66 & 9.17 & 647.21 & 55.96 & 87.21 & 2.96 & 18.91 & 175.20 & 1.71 & 0.02 & 0.02 & 0.04 & 1.67 & 0.72 & 10.29 \\
\hline Cluster 2 & Mean & 2.17 & 11.84 & 9.58 & 987.26 & 109.34 & 13.74 & 6.04 & 14.25 & 165.99 & 1.84 & 0.02 & 0.05 & 0.07 & 4.61 & 0.79 & 0.84 \\
\hline \multirow{3}{*}{$\begin{array}{l}\text { L911, L3234, } \\
\text { L5522, L5527 }\end{array}$} & $\operatorname{Max}$ & 3.05 & 17.40 & 14.34 & 1129.04 & 127.58 & 45.58 & 7.48 & 32.09 & 199.25 & 2.17 & 0.03 & 0.06 & 0.10 & 7.73 & 1.25 & 3.46 \\
\hline & Min & 1.45 & 6.53 & 4.68 & 844.00 & 92.02 & -23.79 & 5.10 & -1.70 & 136.48 & 1.54 & 0.01 & 0.04 & 0.05 & 2.54 & 0.45 & -3.20 \\
\hline & Range & 1.60 & 10.87 & 9.66 & 285.04 & 35.56 & 69.37 & 2.38 & 33.79 & 62.77 & 0.63 & 0.02 & 0.02 & 0.05 & 5.19 & 0.80 & 6.66 \\
\hline Cluster 3 & Mean & 1.81 & 11.36 & 9.55 & 466.83 & 116.46 & 29.73 & 7.23 & -6.05 & 254.47 & 3.31 & 0.04 & 0.04 & 0.07 & 2.19 & 1.18 & -0.24 \\
\hline L143, L710, & Max & 2.35 & 16.50 & 14.31 & 996.63 & 150.21 & 89.03 & 12.25 & 0.24 & 661.89 & 5.08 & 0.06 & 0.06 & 0.10 & 4.92 & 2.97 & 3.51 \\
\hline L917, L1214, & Min & 1.13 & 5.70 & 4.56 & 149.13 & 76.64 & -27.19 & 5.85 & -14.31 & 111.20 & 1.17 & 0.01 & 0.02 & 0.03 & 0.77 & 0.55 & -3.56 \\
\hline ZM421, ZM521 & Range & 1.22 & 10.80 & 9.75 & 847.50 & 73.57 & 116.22 & 6.40 & 14.55 & 550.69 & 3.91 & 0.05 & 0.04 & 0.07 & 4.15 & 2.42 & 7.07 \\
\hline
\end{tabular}

* IRL = Initial root length, FRL $=$ Final root length, ARL = Actual root length, SRL = specific root length, RRL = relative root length, RLR $=$ Root length response, $\mathrm{SL}=$ shoot length, SLR $=$ Shoot length response, SLSDMratio $=$ Shoot length-shoot dry matter ratio, RDM $=$ root dry matter, $\mathrm{SDM}=$ shoot dry matter, TDM $=$ total dry matter, $\mathrm{SRDM}$ ratio = shoot-root dry matter ratio, NOR = number of roots, SLRL Ratio = shoot root length ratio, and $\mathrm{NRG}=$ net root growth. 
Table 9. Membership index for the 14 maize genotypes based on three selected root traits.*

\begin{tabular}{|c|c|c|c|c|c|c|c|c|}
\hline \multirow{2}{*}{ Genotype } & \multicolumn{2}{|c|}{ ARL } & \multicolumn{2}{|c|}{ RRL } & \multicolumn{2}{|c|}{ RLR } & \multicolumn{2}{|c|}{ Mean } \\
\hline & Score & Class & Score & Class & Score & Class & Score & Class \\
\hline POOL16 & 0.32 & $\mathrm{~S}$ & 0.34 & $\mathrm{~S}$ & 0.29 & $\mathrm{~S}$ & 0.32 & $\mathrm{~S}$ \\
\hline L12 & 0.52 & I & 0.51 & I & 0.49 & I & 0.51 & I \\
\hline L143 & 0.38 & $\mathrm{~S}$ & 0.37 & S & 0.34 & S & 0.36 & $\mathrm{~S}$ \\
\hline L710 & 0.30 & S & 0.34 & S & 0.27 & S & 0.30 & S \\
\hline L911 & 0.14 & HS & 0.26 & S & 0.11 & HS & 0.17 & HS \\
\hline L913 & 0.34 & S & 0.31 & S & 0.32 & S & 0.32 & S \\
\hline L917 & 0.16 & HS & 0.11 & HS & 0.14 & HS & 0.14 & HS \\
\hline L1214 & 0.82 & HT & 0.78 & $\mathrm{~T}$ & 0.83 & HT & 0.81 & HT \\
\hline L3233 & 0.74 & $\mathrm{~T}$ & 0.82 & HT & 0.84 & HT & 0.80 & HT \\
\hline L3234 & 0.59 & I & 0.57 & I & 0.56 & I & 0.57 & I \\
\hline ZM421 & 0.49 & I & 0.76 & $\mathrm{~T}$ & 0.72 & $\mathrm{~T}$ & 0.66 & $\mathrm{~T}$ \\
\hline ZM521 & 0.50 & I & 0.56 & I & 0.57 & I & 0.54 & I \\
\hline L5522 & 0.20 & S & 0.28 & S & 0.25 & S & 0.24 & S \\
\hline L5527 & 0.60 & $\mathrm{~T}$ & 0.59 & $\mathrm{I}$ & 0.61 & $\mathrm{~T}$ & 0.60 & $\mathrm{~T}$ \\
\hline
\end{tabular}

\section{Discussion}

\subsection{Correlation among Seedling Traits}

Root length measurement is one of the primary criteria used for evaluation for aluminum tolerance in hydroponic conditions [36,37]. Other traits like ratio of root to shoot fresh weight [38], total dry weight of the roots, and total dry weight of the shoots have been used for identifying aluminum-tolerant genotypes. However, the inter-correlations among the traits may provide challenges for their effective utilization, as the desired trait could be positively correlated to an undesirable trait. The classification of ZM421 and ZM521 being tolerant to aluminum toxicity was unexpected as the two populations were developed for low and drought tolerance (http://r4d.dfid.gov.uk/Project/60389/Default.aspx, accessed 6 March 2015). This could be attributed the fact that selection for drought tolerance was sometimes done on soils with a pH below $4.5[39,40]$, which could have resulted in co-selection for aluminum tolerance [34]. The observation made in this study is supported by the susceptibility of the variety, pool 16, which was developed for drought tolerance based on drought escape through early maturity. In addition, studies have also confirmed that selection for drought and low nitrogen tolerance in southern Africa has resulted in generating hybrids with wide adaptation [41]. Therefore, ZM421 and ZM521 populations should be exploited for the generation of inbred lines that are tolerant to aluminum toxicity.

Selection shapes the genetic make-up and thus targeted genetic improvement for aluminum tolerance will depend on the existence of genetic variation and identification of traits that are correlated to grain yield. Studies have shown that seminal root length and root dry weight are highly correlated to field grain yield under low and high nitrogen conditions, while total root length and root dry weight are strongly correlated to nutrient and water use efficiency in maize $[42,43]$. The relative 
net root growth (RNRG) of maize inbred lines under hydroponic conditions is positively correlated to field performance of maize under aluminum toxicity, explaining between $24 \%$ and $35 \%$ [19]. All these research findings suggest that multiple routes can be used for stress tolerance breeding towards aluminum tolerance, and therefore each breeding program should find the optimal trait to use.

In this study, SRDM ratio was negatively correlated to all root traits (FRL, IRL, ARL, NOR, $\mathrm{TDMm}$ and $\mathrm{RDM}$ ), indicating that there was a tendency for the plants to preferentially allocate resources to the roots as opposed to the shoots. However, the resources allocated to the roots were mostly used for root maintenance rather than root growth. This is supported by the significantly high negative correlations between SRL and NOR $(r=-0.73)$, and between SRL and RDM $(r=-0.76)$; the moderate negative correlation of SRL with TDM $(r=-0.50)$; and the weak negative correlation of SRL with SDM $(r=-0.14)$. Blair et al. (2009) observed a negative correlation between SRL and SRDM ratio in beans under aluminum toxicity. In this study, a strong positive correlation between SRL and SRDM ratio was observed, suggesting that increasing SRL will result in increasing the dry matter partitioned to the shoot rather than the roots in cereals.

Specific Root Length (SRL) is the index of root benefit to root cost, whereby root length is proportional to acquiring resources and root mass is proportional to construction and maintenance [27]. SRL integrates roo length with root fineness, thereby representing the exploration and resource uptake of the plant; it has therefore been suggested as a useful trait in breeding [27,44]. Plants with high SRL build more root length for a given dry mass and are preferred as they have higher nutrient and water uptake [45]. Although high SRL is associated with high nutrient uptake, RGR, and water use efficiency, the trait has a short life span [46]. It is also important to note that high SRL is also associated with low tissue density or low diameter. Inbred lines L3233 and L1214 had high SRL and high RRL, indicating that more dry matter was allocated to root length, which could have resulted in increased uptake and thus sustained growth. The second highest inbred line for SRL was L3234, but it had intermediate RRL. This genotype (L3234), however, could have allocated more dry matter to root development such that growth was inhibited greatly, which resulted in medium aluminum tolerance. On the other hand, L911 had high SRL and low RRL, implying that more dry matter was allocated to root maintenance. In this regard, inbred lines L3233 and L1214 are potentially useful for aluminum tolerance breeding.

\subsection{Phenotypic and Genotypic Coefficients of Variation, Heritability, and Genetic Advance as Percent of the Mean}

The genetic improvement for aluminum toxicity will depend on the amount of genetic variability and heritability of the trait. Since the genetic variation might be heritable or non-heritable, estimating the heritability of the trait is important. The observed phenotypic variability is partitioned into heritable and non-heritable components with the phenotypic and genotypic coefficient of variation, heritability, and genetic advance [47]. The broad sense heritability $\left(\mathrm{H}^{2} \mathrm{bs}\right)$ provides information on the relative magnitude of genetic and environmental variation [48]. Therefore, $\mathrm{H}^{2}$ bs is of little help to breeders if the genetic gain (GG) of the trait is not known as it provides the breeder with the expected genetic progress made during breeding. In the present study, most of the traits had high heritability coupled with high genetic gain, suggesting a preponderance of additive gene effects $[49,50]$. Therefore, the 
traits with high $\mathrm{H}^{2}$ bs and GG can be used for selecting for aluminum tolerance [51,52]. Based on these propositions, all traits are potentially useful as selection traits except for RRL. Furthermore, all the traits in this study had almost equal GCV and PCV, which is acceptable, although breeders desire higher GCV than PCV [49].

\subsection{Principal Component Analysis and Cluster Analysis}

Many root traits and their responses to aluminum toxicity have been used in breeding and selection of tolerant genotypes in cereals [53,54]. Principal component analysis can be used to identify the most influential traits, so first two PCs were used to identify influential traits. All important traits (loadings $\geq 0.30$ ) in PC1 and PC2 were considered influential. The inter-relationships between the traits were considered and six traits out of 13 were identified as potential for selection. These traits had high heritability and genetic gain; however, the order of importance based on genetic gain are NRG, SLR, SLRLratio, FRL, SRL, and RRL.

The dendrogram based on the seedling traits allowed for the categorization of the 14 genotypes into three main clusters. Clear distinctions were discerned between inbreds L3233 and L5522, the heterotic patterns of southern Africa. The three populations were also clearly separated, with ZM421 and ZM521 in one cluster and pool16 in another cluster. The population pool 16 represents early breeding for drought tolerance through escape. On the other hand, ZM421 and ZM521 represent recent developments in breeding for multiple stress tolerance.

\subsection{Implications on Plant Breeding in Zambia}

Substantial variation in maize inbred line response to aluminum concentration was observed as evidenced by the highly significant genotype by environment interaction. This indicates that the comprehensive maize hybrid breeding program that was used in the early years [52] had resulted in co-selection for aluminum tolerance, especially when the breeding focused on developing drought-tolerant genotypes in the late 1980s [53]. Studies have shown that breeding for drought tolerant results in aluminum tolerance [54]. Therefore, co-selection for aluminum tolerance could have occurred, just as Masole and Gumbo (1980) reported good genetic gain for drought tolerance and earliness during breeding. Despite this, the traits that confer tolerance to aluminum toxicity were not highly concentrated in the inbred lines as selection for aluminum tolerance was not done. Now that there are many hybrids on the market, breeding for specific adaptation or ecological regions is the major focus of the Zambian breeding program. The observed variation for aluminum tolerance in maize germplasm can be enhanced for breeding. Based on the overall classification of maize inbred lines, the mode of gene action can be studied by making crosses among the different tolerance classes. Furthermore, populations can be formed by inter-mating the highly tolerant, tolerant, and intermediate inbred lines. The resulting populations can then be improved for yield performance under $\mathrm{Al}$ conditions. These populations would later be used for extracting inbred lines. In addition, exotic inbred lines that are tolerant to low $\mathrm{pH}$ or $\mathrm{Al}$ concentration can be systematically introgressed in these inbreds. 


\section{Conclusions}

The observed genetic variation of maize inbred lines in response to aluminum concentration can be exploited for developing aluminum tolerant hybrids. The high heritability and genetic advance over mean observed in most of the root traits indicates that additive gene action is at play. Therefore, selection for these traits would result in genetic gain and breeding progress. NRG, SLR, and RLR with high heritability and genetic gain are traits that should be used for selection. NRG had the highest genetic gain followed by SLR, supporting the superiority of root traits in evaluating for aluminum tolerance. The root tolerance index that incorporates many traits should be used to identify tolerant genotypes. The two populations found to be tolerant to aluminum toxicity, ZM421 and ZM521, should be used in breeding works.

\section{Acknowledgments}

The financial assistance of RUFORUM is acknowledged. The experiment was carried out with the support of the University of Zambia, Department of Plant Sciences. The work was part of the studies conducted by Chanda Richard and Theresa Kinkese. The constructive comments and suggestions of anonymous reviewers on the earlier draft are gratefully acknowledged.

\section{Author Contributions}

All Authors contributed equally to the work.

\section{Conflicts of Interest}

The authors declare no conflict of interest.

\section{References}

1. Kumwenda, J.D.T.; Waddington, S.R.; Snapp, S.S.; Jones, R.B.; Blackie, M.J. Soil fertility management research for the maize cropping systems of smallholders in southern africa: A review. In NRG Paper; CIMMYT: Mexico, DF, Mexico, 1996; Volume 96-02, p. 30.

2. Duraes, F.M.; Gama, E.E.G.; Magalhaes, P.C.; Marriel, I.E.; Casela, C.R.; Oliveira, A.C.; Luchiari-Junior, A.; Shanahan, J.F. The Usefulness of Chlorophyll Fluorescence in Screening for Disease Resistance, Water Stress Tolerance, Aluminum Toxicity Tolerance and Nitrogen Use Effeciency in Maize. In Proceedings of the Seventh Eastern and Southern Africa Regional Maize Conference, Harare, Zimbabwe, 11-15 February 2001; pp. 356-360.

3. Gudu, S.O.; Okalebo, J.R.; Othieno, C.O.; Obura, P.A.; Ligeyo, D.O.; Shulze, D.; Johnston, C. Response of five maize genotypes to nitrogen, phosphorus and lime on acid soils of western kenya. Afr. Crop Sci. 2005, 7, 1109-1115.

4. Foy, C.D. Physiological effects of hydrogen, aluminum and manganese toxicities in acid soils. In Soil Acidity and Liming, Agronomy Monograph 12, 2nd ed.; Adams, F., Ed.; American Society of Agronomy: Madison, WI, USA, 1984; pp. 57-97. 
5. Fageria, N.K.; Baligar, V.C.; Wright, R.J. Alumimium toxicity in crop plants. J. Plant Nutr. 1988, $11,303-319$.

6. Donovan, C.; Damaseke, M.; Govereh, J.; Simumba, D. Framework and initial analyses of fertilizer profitabillity in maize and cotton. In Food Security Research Project; CIMMYT: Harare, Zimbabwe, 2002; pp. 1-64.

7. Tveitnes, S.; Svads, H. The effect of lime on maize and groundnut yields in the high rainfall areas of zambia. Nowegian J. Agric. Sci. 1989, 3, 173-180.

8. Malama, C.N. Evaluating the agronomic potential of tithonia diversifolia prunings in the acid soils on nothern Zambia. In Proceedings of the Seventh Eastern and Southern Africa Regional Maize Conference, Harare, Zimbabwe, 11-15 February 2001; pp. 372-376.

9. Caniato, F.F.; Guimaraes, C.T.; Hamblin, M.; Billot, C.; Rami, J.; Hufnagel, B.; Kochian, L.V.; Liu, J.; Garcia, A.A.F.; Hash, C.T.; et al. The relationship between population structure and aluminum tolerance in cultivated sorghum. PLOS ONE 2011, 6, e20830.

10. Mason, N.M.; Burke, W.J.; Shipekesa, A.; Jayne, T.S. The 2011 surplus in smallholder maize production in Zambia: Drivers, beneficiaries, and implications for agricultural and poverty reduction policies. In Food Security Research Project; CIMMYT: Harare, Zimbabwe, 2011; p. 35.

11. Bwembya, S.; Yerokun, O.A. Effect of cassia spectables, cowdung and their combination on growth and grain yield on maize. In Proceedings of the Seventh Eastern and Southern African Regional Maize Conference, Harare, Zimbabwe, 11-15 February 2001; pp. 361-366.

12. Munyinda, K. Climate change in Zambia; Chanda, R., Ed.; CIMMYT: Lusaka, Zambia, 2010.

13. The, C.; Calba, H.; Zonkeng, C.; Zonkeng, C.; Ngonkeu, E.L.M.; Adetimirin, V.O.; Mafouasson, H.A.; Meka, S.S.; Horst, W.J. Responses of maize grain yield to changes in acid soil characteristics after soil ammendments. Plant Soil 2006, 284, 45-57.

14. Magalhaes, J.V.; Garvin, D.F.; Wang, Y.; Sorrels, M.E.; Klein, P.E.; Schaffert, R.E.; Li, L.; Kochian, L.V. Comparative mapping of major $\mathrm{Al}^{3+}$ tolerance gene in sorghum and other species in the poaceae. Plant Genet. 2004, 167, 1905-1914.

15. The, C.; Calba, H.; Horst, W.J.; Zonkeng, C. Maize grain yield correlated responses to change in acid soil characteristics after 3years of soil ammendments. In Proceedings of the Seventh Eastern and Southern Africa Region Maize Conference, Harare, Zimbabwe, 11-15 February 2001; pp. 222-227.

16. Okiyo, T.; Gudu, S.; Kiplagia, O.; Owuoche, J. Combining drought and aluminum toxicity tolerance to improve sorghum productivity. Afr. Crop Sci. J. 2010, 18, 147-154.

17. Urrea-Gomej, R.; Ceballos, H.; Pandey, S.; Bahia-Filho, A.F.C.; Lenin, L.A. A greenhouse screening technique for acid soil tolerance in maize. Agron. J. 1996, 88, 806-812.

18. Ouma, E.; Ligeyo, D.; Matonyei, T.; Agalo, J.; Were, B.; Too, E.; Onkware, A.; Gudu, S.; Kisinyo, P.; Nyangweso, P. Enhancing maize grain yield in acid soils of western kenya using aluminum tolerance germplasm. J. Agric. Sci. Technol. 2013, 3, 33-46.

19. Abdel-Ghani, A.H.; Kumar, B.; Reyes-Matamoros, J.; Gonzalez-Portilla, P.J.; Jansen, C.; Martin, J.P.S.; Lee, M.; Lubberstdt, T. Genotypic variation and relationships between seedling and adult plant traits in maize (Zea Mays L.) inbred lines grown under contrasting nitrogen levels. Euphytica 2012, 189, doi:10.1007/s10681-012-0759-0. 
20. Kumar, B.; Abdel-Ghani, A.H.; Reyes-Matamoros, J.; Hochholdinger, F.; Lubberstdt, T. Genotypic variation for root architecture traits in seedlings of maize (Zea Mays L.) inbred lines. Plant Breed. 2012, 131, 465-478.

21. DeSousa, S.M.; Clark, R.T.; Mendes, F.F.; deOliveira, A.C.; deVasconcelos, M.J.V.; Paretoni, S.N.; Kochian, L.V.; Guimaraes, C.T.; Magalhaes, J.V. A role for root morphology and related candidate genes in p acquisition effeciency in maize. Funct. Plant Biol. 2012, 39, 925-935.

22. Makau, M.; Masito, S.S.; Gweyi-Onyango, J.P. A rapid hydroponic screening of field and horticultural crops for aluminium tolerance. Afr. J. Hort. Sci. 2011, 4, 48-59.

23. Kerridge, P.C.; Dawson, M.D.; Moore, D.P. Separation of degrees of aluminium tolereance in wheat. Agron. J. 1971, 63, 568-591.

24. Choudhary, A.K.; Singh, D.; Kumar, J. A comparative study of screening methods for tolerance to aluminum toxicity in pigeonpea (Cajanus Cajan (L.) millspaugh). Aust. J. Crop Sci. 2011, $5,1419$.

25. Anas; Yoshida, T. Screening of al-tolerant sorghum by hematoxylin staining and growth response. Plant Prod. Sci. 2000, 3, 246-253.

26. Blair, M.W.; López-Marín, H.D.; Rao, I.M. Identification of aluminum resistant Andean common bean (Phaseolus vulgaris L.) genotypes. Braz. J. Plant Physiol. 2009, 21, 291-300.

27. Gai, J.; Liu, Y.; Liu, H.; Zhao, T.; Yu, D. Identification of Mutatnts with Tolerance to Rhizospheric Stresses and Inheritance and qtl Mapping of Rewlated Root Traits in Soyabean. Available online: http//mvgs.iaea.org/PDF/TECDOC149304.pdf (accessed on 18 June 2014).

28. Suwarno, W.B.; Sobir; Aswidinnoor, H.; Syukur, M. Pbstat: A web-based statistical analysis software for participatory plant breeding. In Proceedings of the 3rd International Conference on Mathematics and Statistics (ICoMS-3), Bogor Agricultural University, Bogor, Indonesia, 5-6 August 2008; p. 7.

29. Singh, R.K.; Chaudhary, B.D. Biometrical Methods in Quantitative Genetics Analysis; Kalyani Publishers: New Delhi, India, 1977.

30. Shivasubramanian, S.; Menon, N. Heterosis and inbreeding depression in rice. Madras Agril. J. 1973, 60, 1139-1144.

31. Johnson, H.W.; Robinson, H.F.; Comstock, R.W. Estimation of genetic and environmental variability in soybean. Agron. J. 1955, 47, 447-483.

32. Robinson, H.F.; Comstock, R.E.; Harvery, V.H. Estimates of heritability and degree of dominance in corn. Agron. J. 1949, 41, 353-359.

33. Trachsel, S.; Stamp, P.D.; Hundi, A. Effect of high temperatures, drought and aluminum toxicity on root growth of tropical maize (Zea Mays L.) seedlings. Maydica 2010, 55, 249-260.

34. Abate, E.; Hussien, S.; Laing, M.; Mengistu, F. Aluminium toxicity tolerance in cereals: Mechanisms, genetic control and breeding methods. Afr. J. Agric. Res. 2013, 8, 711-722.

35. Ringo, J.H.; Mneney, E.E.; Onkware, A.O.; Were, B.A.; Too, E.J.; Owuoche, J.O.; Gud, S.O. Tolerance to aluminium toxicity in Tanzanian sorghum genotypes. Afr. Crop Sci. J. 2010, 18, 155-164.

36. Krstic, D.; Djalovic, I.; Nikezic, D.; Bjelic, D. Aluminium in acid soils: Chemistry, toxicity and impact on maize plants. In Food Production-Approaches, Challenges and Tasks; Aladjadjiyan, A., Ed.; INTECH: Rijeka, Croatia, 2012; pp. 231-242. 
37. Ma, J.F.; Nagao, S.; Sato, K.; Ito, H.; Furukawa, J.; Tekda, K. Mollecular mapping of gene responsible for al-activated secretion of citrate in barley. J. Exp. Bot. 2004, 55, 1335-1341.

38. Nyamangara, J.; Mugwira, L.M.; Mpofu, S.E. Soil fertility status in the commercial areas of Zimbabwe in relation to sustainable crop production. J. Sustain. Agric. 2005, 16, 15-29.

39. Bänziger, M.; Setimela, P.S.; Hodson, D.; Vivek, B. Breeding for improved drought tolerance in maize adapted to southern Africa. Agric. Water Manag. 2006, 80, 212-224.

40. Weber, V.S.; Melchinger, A.E.; Magorokosho, C.; Makumbi, D.; Bänziger, M.; Atlin, G.N. Effieciency of managed-stress screening of elite maize hybrids under drought and low nitrogen for yield under rainfed conditions in southern africa. Crop Sci. 2012, 52, 1011-1020.

41. Løes, A.K.; Gahoonia, T.S. Genetic variation in specific root length in Scandinavian wheat and barley accessions. Euphytica 2004, 137, 243-249.

42. Paula, S.; Pausa, J.G. Root traits explain different foraging strategies between resprouting life histories. Oecologia 2011, 165, 321-331.

43. Pérez-Harguindeguy, N.; Díaz, S.; Garnier, E.; Lavorel, S.; Poorter, H.; Jaureguiberry, P.; Bret-Harte, M.S.; Cornwell, W.K.; Craine, J.M.; Gurvich, D.E.; et al. New handbook for standardised measurement of plant functional traits worldwide. Aust. J. Bot. 2013, 61, 167-234.

44. Mohamed, S.M.; Ali, E.E.; Mohamed, T.Y. Study of heritability and genetic variability among differrent plant and fruit characters of tomato (Solanum lycopersicon L.). Int. J. Sci. Technol. Res. 2012, 1, 55-58.

45. Dudley, J.W.; Moll, R.H. Interpretation and use of estimates heritability and genetic variances in plant breeding. Crop Sci. 1969, 9, 257-262.

46. Bello, O.B.; Ige, S.A.; Azeez, M.A.; Afolabi, M.S.; Abdulmaliq, S.Y.; Mahamood, J. Heritability and genetic advance for grain yield and its component characters in maize (zea mays 1.). Int. J. Plant Res. 2012, 2, 138-145.

47. Devi, N.D.; Mariappan, S. Genetic variability, heritability and genetic advance for yield and its components snake gourd (Trichosanthes anguina L.). Afr. J. Agric. Res. J. Agric. Sci. 2013, 8, 3857-3859.

48. Boakye, P.B.; Kwadwo, O.; Isaac, A.K.; Parkes, E.Y. Genetic variability of three cassava traits across three locations in Ghana. Afr. J. Plant Sci. 2013, 7, 265-267.

49. Hosseini, S.J.; Sarvestani, Z.T.; Pirdashti, H.; Afkhami, A.; Hazrati, S. Estimation of heritability and genetic advance for screening some rice genotypes at salt stress conditions. Int. J. Agron. Plant Prod. 2012, 3, 475-482.

50. Nasr, N.; Carapetian, J.; Heidari, R.; Rezaei, S.A.; Abbaspour, N.; Darvishzadeh, R. Differential effects of aluminium on the seedling parameters of wheat. Afr. J. Biotechnol. 2011, $10,3345-3353$.

51. Roy, B.; Bhadra, S. Effect of toxic levels of aluminium on seedling parameters of rice (Oryza sativa L.) under hydroponic culture. Rice Sci. 2014, 21, 9.

52. Masole, H. An assessment of maize development in Zambia. Afr. Crop Sci. Soc. 1997, 3, 747-753.

53. Masole, H.; Gumbo, M. Performance of early to medium maturity maize genotypes during the 1991-1992 drought in Zambia. In Proceedings of the Maize Research for Stress Environments: Fourth Eastern and Southern African Regional Maize Conference, Harare, Zimbabwe, 28th March-1st April 1994; pp. 117-121. 
54. Magalhaes, P.C.; de-Souza, T.C.; Cantao, F.R.O.; Padilha, F.A. Root morphology of maize with contrasting drought resistance under three toxic levels of aluminum. Revista Brasileira de Milho e Sorgo 2012, 11, 35-48.

(C) 2015 by the authors; licensee MDPI, Basel, Switzerland. This article is an open access article distributed under the terms and conditions of the Creative Commons Attribution license (http://creativecommons.org/licenses/by/4.0/). 